\title{
POLÍTICA Y CREACIÓN LITERARIA EN LA PRENSA DE CHIAPAS (1910-1912)
}

POLITICS AND LITERARY CREATION IN CHIAPAS PRESS

(1910-1912)

Rafael de Jesús Araujo González

fayeyo@msn.com 
Para citar este artículo:

Araujo González, Rafael. (2019). Política y creación literaria en la prensa de Chiapas (1910-1912). Espacio I+D, Innovación más Desarrollo. VIII(21), 134-154. doi: http://dx.doi. org/10.31644/IMASD.21.2019.a08

\section{RESUMEN}

Con base en una revisión hemerográfica, se comentan epigramas y versos misceláneos aparecidos en diarios de Chiapas para demostrar cómo los acontecimientos políticos y sociales de la revolución maderista (1910-1911) impactaron en el campo de la creación literaria. Al identificar autores, los diarios donde fueron publicados y sus nexos con personajes públicos, este artículo se suma al estudio sobre las relaciones entre literatura y política durante la primera mitad del siglo XX.

\section{Palabras clave}

Literatura; Chiapas; revolución; prensa; poder político. 


\section{- Abstract-}

In base to a journalistic research on dailies from Chiapas, epigrams and different kind of verses are commented in order to demonstrate how the social and political events of the Maderista revolution (1910-1911) influenced the field of literary creation. As long as it identifies authors, the journals where these ones were published and their political networking, this article contributes to the study of the relationship between literature and politics during the first half of the twentieth century.

\section{Keywords}

Literature; Chiapas; revolution; press; political power. 
L a influencia de los acontecimientos políticos y sociales en la creación literaria de Chiapas, es demostrable por la revisión de los periódicos locales resguardados en la Hemeroteca Fernando Castañón Gamboa (HFCG) de la Universidad de Ciencias y Artes de Chiapas y por el trabajo de diversos estudiosos del tema. El periodo comprendido entre los años 1901 y 1913 da cuenta de un cambio en la cantidad y calidad de textos literarios durante los últimos años de estabilidad política nacional, bajo el mandato del General Porfirio Díaz, y la ascensión y caída del régimen maderista.

Los presupuestos de la afirmación anterior son tres. Primero, el vínculo establecido entre la prensa ${ }^{1} \mathrm{y}$ grupos de poder; segundo, el uso de periódicos locales para divulgar textos de creación literaria que denuestan o aplauden a personajes públicos durante conflictos políticos; y tercero, las relaciones entre los intelectuales chiapanecos residentes en el centro del país y los escritores radicados en Tuxtla Gutiérrez, San Cristóbal de Las Casas y Comitán, quienes se sirvieron de los diarios de la entidad para promover intereses que rebasaban los del campo estrictamente literario.

A continuación se presenta información sobre el contexto político de Chiapas, posteriormente se muestran ejemplos de los textos literarios publicados antes, durante y después de los acontecimientos más relevantes del periodo en estudio, a fin de compararlos y visualizar sus cambios en cantidad y calidad.

\section{CONTEXTO POLÍTICO (1900-1915)}

Al llegar a Chiapas, el visitante se asombra de la diversidad y contraste de su territorio. Además de su variedad de ecosistemas, su riqueza cultural está opacada por la miseria en que sobrevive la mayoría de sus habitantes.

Esta entidad federativa se incorpora al país en 1824, tres años después de la independencia de los Reinos de Nueva España y de la Capitanía General de Guatemala del dominio europeo, en 1821. Uno de los argumentos para esta federalización fue la ausencia de acciones a favor del desarrollo económico y social de la entidad durante la Colonia.

Por su ubicación geográfica, y específicamente por su orografía, Chiapas estuvo aislado de otras regiones, ya fueran de la Nueva España, de la Capitanía General de Guatemala o mexicanas, situación que incidió en la miseria económica del grueso de su población y que explica, también, la singular repercusión de los acontecimientos nacionales en la cotidianidad

1 La existencia de libros es limitada, sea porque se perdieron con el paso de los años o porque no se escribieron. 
local. La relación con el gobierno mexicano fue de un aparente y superficial sometimiento, desmentido luego en la relativa autonomía con que las élites chiapanecas dirimían las decisiones políticas y económicas del estado.

A la llegada del ocaso porfirista y con el cambio de siglo, Chiapas vivió bajo el mandato del General Díaz y del grupo local encabezado por Emilio Rabasa, político cercano a los colaboradores del presidente. Ángel Pola (2012, pp. 28-29) ${ }^{2}$ cuenta en su “Autobiografía” cómo, a finales del siglo XIX y principios del XX, él y Rabasa se reunían periódicamente en la Ciudad de México junto a los chiapanecos Manuel Lacroix, Víctor Manuel Castillo, José María Pascacio, Juan María Esponda, Marín Llaven y José Antonio Rivera G. Varios de los nombrados se convirtieron en figuras relevantes de la política chiapaneca luego de construir, ampliar y mantener redes en la capital del país con personajes influyentes en la política y la economía nacionales.

En la siguiente relación de gobernadores y presidentes del Congreso del Estado de 1901 a 1915 (tabla 1) es evidente la influencia del ex gobernador Rabasa en su ayuda, primero, a Rafael Pimentel (compañero de estudios profesionales), y después en el impulso a su hermano para la obtención de sendas gubernaturas del estado.

\section{Tabla 1}

Relación de gobernadores y presidentes del congreso local 1901-1915

\begin{tabular}{ccc}
\hline Año & Gobernador & Presidente del Congreso del Estado \\
1901 & Rafael Pimentel & Daniel A. Zepeda \\
1902 & Rafael Pimentel & Ciro Farrera \\
1903 & Rafael Pimentel & Eleuterio Aguilar \\
1904 & Rafael Pimentel & Sin identificar \\
1905 & Rafael Pimentel & Miguel A. Castillo \\
1906 & Ramón Rabasa & Eliseo López \\
1907 & Ramón Rabasa & Enoch Paniagua \\
1908 & Ramón Rabasa & Andrés Contreras \\
1909 & Ramón Rabasa & Bernardo Martínez Baca \\
1910 & Ramón Rabasa & Prudencio Pastrana \\
& Manuel Trejo & \\
& Reinaldo Gordillo León (Interino) & Policarpo Rueda \\
1911 & Manuel Rovelo Argüello & Sin identificar \\
& Querido Moheno (quien no pudo & \\
& tomar posesión) & \\
& Reinaldo Gordillo León (Electo) &
\end{tabular}

2 Valente Molina presenta esta información como cita textual de la revista Chiapas y México (s/d) en su libro La colonia chiapaneca en el Distrito Federal. 1888-1950. 


\begin{tabular}{|c|c|c|}
\hline 1912 & $\begin{array}{l}\text { Reinaldo Gordillo León } \\
\text { Flavio A. Guillén }\end{array}$ & Sin identificar \\
\hline 1913 & $\begin{array}{c}\text { Flavio A. Guillén } \\
\text { Reinaldo Gordillo León } \\
\text { Bernardo Z. Palafox }\end{array}$ & Teófilo Castillo Corzo \\
\hline 1914 & $\begin{array}{c}\text { Bernardo Z. Palafox } \\
\text { Jesús Agustín Castro } \\
\text { Blas Corral }\end{array}$ & Sin identificar \\
\hline 1915 & Blas Corral & Sin identificar \\
\hline
\end{tabular}

Fuente: elaborado a partir de los informes de gobierno respectivos, consultados en el Archivo Histórico de Chiapas, en la UNICACH y del libro Chiapas: Notas para una historia reciente (1994), de Luis Enrique Pérez Mota.

Raúl Serrano Aranda (2010, pp. 86-87) considera que Rafael Pimentel, militar como el General Porfirio Díaz, es derrocado del gobierno por conflictos ${ }^{3}$ con Rabasa: "Rabasa finalmente ganó la batalla. Pimentel renunció cuando le faltaban dos años para concluir su período que debía ser hasta 1907". Comparte la opinión Luis Enrique Pérez Mota: "En el centro de la discusión se encontraban el ex gobernador Emilio Rabasa y su escuela política: el rabasismo. Las recurrentes impugnaciones se concentraban en malograr su figura y su trabajo al frente de la entidad" (1994, pp. 15-16).

A la caída de la administración del General Díaz, los problemas para el rabasismo están vinculados a los siguientes factores:

1. Aislamiento de la entidad respecto a la federación y a otros estados, situación que permitió la consolidación de Rabasa como el líder político moral de Chiapas en virtud de su proximidad a los colaboradores cercanos del General Díaz, sus relaciones con los grupos políticos chiapanecos - a excepción de las élites de San Cristóbal de Las Casas- y su reconocida trayectoria como jurista y político.

2. La revolución maderista, aprovechada por un grupo vinculado a San Cristóbal para lograr la destitución de Ramón Rabasa e impulsar el regreso de los poderes y del control político del estado a su localidad. El argumento principal fue la vinculación de Emilio Rabasa con el régimen del General. El grupo estuvo vinculado con la iglesia y utilizó como presión el apoyo del Partido Católico a Francisco I. Madero.

3. El conflicto revolucionario posterior al asesinato de Madero. La disputa armada brindó a los grupos políticos la oportunidad de

3 Las discrepancias tienen su origen en el ejercicio del poder. Pimentel tomó decisiones contrarias a los intereses de Rabasa. 
ascender al poder local con base en su demostración de control sobre grupos sociales y sus relaciones con la autoridad central (gobierno federal).

En este contexto nacional, la pugna entre los grupos se agudiza y desencadena conflictos armados conforme cambia el mando del poder ejecutivo local, tal como sucedió durante la rebelión sancristobalense, bajo el argumento de ser ésta parte del movimiento maderista y ubicando al gobierno del estado - así como a Rabasa y sus amigos - en el bando porfirista. La prensa chiapaneca registra este conflicto de manera puntual.

Los periódicos chiapanecos estuvieron vinculados con tres sectores influyentes entre la población: el político, el académico-intelectual y el económico. De manera menos importante, con la iglesia, representada por el obispado. El papel desempeñado por esta institución fue opacado por el rumbo de los acontecimientos nacionales.

\section{LOS PERIÓDICOS, INSTRUMENTO DEL PODER}

En La prensa maniatada. El periodismo en Chiapas de 1827 a 1958, Sarelly Martínez informa sobre la utilización de los periódicos como instrumentos de propaganda política e ideológica:

De los 90 periódicos editados en Chiapas, 67 fueron de orientación política; seis, especializados en jurisprudencia, agricultura y educación; cinco, literarios; cinco, órganos de agrupaciones gremiales; cuatro, escolares, y cuatro, religiosos.

De los 67 periódicos políticos, al menos 20 fueron creados para apoyar candidaturas a puestos de elección popular, y es que en aquellos años la prensa realizaba las funciones de un partido político, al promover candidatos y organizar a sus simpatizantes. Fueron de este tipo: El Iris, La Conciliación, El Chichicaste, El Eco Liberal, El Heraldo del Porvenir, El Demócrata, El Zurriago, El Voto Público, El Trueno, El Sentimiento Nacional, El Eco de la Frontera, El Dos de Abril, La Voz del Sur, La Voz del Pueblo, El Voto de Chiapas, El Eco de Comitán, El Club Popular, El 5 de Mayo, El Porvenir y La Idea Democrática. No es raro, por tanto, observar que la etapa de mayor surgimiento de periódicos fuera en los años de actividad electoral, y que disminuyera después de haber pasado la efervescencia política. (2004, 109-110).

Los periódicos permiten reconstruir redes sociales y acontecimientos en su secuencia temporal porque registran puntualmente determinados sucesos y personajes. Por ejemplo, en El plan de San Luis, en su edición del $1^{\circ}$ de junio de 1911 (pp. 1-2), aparece publicada una carta abierta que da cuenta del grupo político de apoyo a la candidatura de Madero al gobierno de la 
república. En ella se dice que la delegación recibida por Don Francisco I. Madero estuvo integrada por "Juan Félix Zepeda, Jesús Martínez Rojas, Alfredo Aguilar, Justo M. Mijangos y Dr. Arturo Aguilar Ruiz”.

La revisión en la HFCG de la prensa correspondiente al periodo 19011912 nos informa sobre la movilidad de quienes encabezaron los periódicos, como se aprecia en la tabla 2. De ésta se desprende que, por ejemplo, Juan F. (Félix) Zepeda, el mismo que estuvo en la reunión con Madero, dirigió 3 periódicos en distintas épocas; otro ejemplo lo da el director de 30-30, Enrique (E.) Barroso, quien había dirigido El Eco, un impreso de Tuxtla Gutiérrez, y también estuvo al frente de por lo menos 2 publicaciones más.

\section{Tabla 2}

Relación de periódicos consultados de 1901 a 1912

\begin{tabular}{|c|c|c|}
\hline Publicación & Director & Ciudad \\
\hline $30-30$ & E. Barroso & Tuxtla Gutiérrez \\
\hline ¡Adelante! & Juan Félix Zepeda & San Cristóbal \\
\hline Chamula G & Isidro Torres & México \\
\hline Diario de Chiapas & E. Barroso & Tuxtla Gutiérrez \\
\hline El Chiquitín & Jesús María Figueroa & Comitán \\
\hline \multirow[t]{3}{*}{ El Clavel Rojo } & Porfirio Gordillo & \\
\hline & L. Flavio Avendaño & Comitán \\
\hline & Gustavo Culebro & \\
\hline El cometa & Luis Espinosa & México \\
\hline El ECO & Enrique Barroso & Tuxtla Gutiérrez \\
\hline El Estado & Juan F. Zepeda & San Cristóbal \\
\hline Elevación & Delfino Coll & Cintalapa \\
\hline El gavilán & Neftalí R. Soto & San Cristóbal \\
\hline El gladiador & Neftalí R. Soto & San Cristóbal \\
\hline \multirow[t]{3}{*}{ El Heraldo de Chiapas } & Bernardo L. Ríos & \\
\hline & Enrique Barroso & Tuxtla Gutiérrez \\
\hline & Lisandro Calderón & \\
\hline El hijo del pueblo & $\begin{array}{c}\text { Hermilo López Sánchez y Genaro Ruiz } \\
\text { de Chávez }\end{array}$ & San Cristóbal \\
\hline El partido liberal & Raquel Cal y Mayor & San Cristóbal \\
\hline El plan de San Luis & G. Coello Lara & San Cristóbal \\
\hline El progreso & Juan J. Conde & Tapachula \\
\hline El pueblo obrero & Mariano Morales R. & Sin identificar \\
\hline El voluntario & Cuauhtémoc Maldonado & San Cristóbal \\
\hline Francisco Cuscate & Ángel B. Coutiño & Tuxtla Gutiérrez \\
\hline ¡Justicia! & Palemón Molina & San Cristóbal \\
\hline La joven Chiapas & Aarón L. García & San Cristóbal \\
\hline
\end{tabular}




\begin{tabular}{ccc} 
La libertad del sufragio & Jesús Alfaro Mijangos & \\
César Martínez Rojas & San Cristóbal \\
La Opinión Pública & Federico Serrano & No legible \\
La paz & Alfonso María Martínez & Tuxtla Gutiérrez \\
La Revista Chiapaneca & Manuel Suárez & San Cristóbal \\
La unión liberal & Alfredo G. Cancino & Comitán \\
La voz de Chiapas & Ramón E. Zepeda & San Cristóbal \\
La verdad & José Ma. Zepeda & Comitán \\
Más allá & J. W. Albores & San Cristóbal \\
Verdady justicia & Juan F. Zepeda & Tuxtla Gutiérrez \\
\hline
\end{tabular}

Fuente: elaborada a partir de la información presente en los impresos incluidos en la tabla.

\section{Tabla 3}

\section{Relación de políticos y prensa local}

\begin{tabular}{|c|c|c|c|c|c|}
\hline Nombre & Actividad política & Año & $\begin{array}{l}\text { Actividad } \\
\text { periodística }\end{array}$ & Periódico & Año \\
\hline \multirow{3}{*}{$\begin{array}{l}\text { Juan Félix } \\
\text { Zepeda }\end{array}$} & $\begin{array}{c}\text { Delegación chiapaneca } \\
\text { que se adhiere a la } \\
\text { candidatura de Francisco } \\
\text { I. Madero }\end{array}$ & 1911 & Director & ¡Adelante! & 1910 \\
\hline & $\begin{array}{c}\text { Integrante del Centro } \\
\text { Directivo de La Libertad } \\
\text { de Sufragio }\end{array}$ & 1911 & Director & El Estado & $1912-1913$ \\
\hline & & & Director & Más allá & 1910 \\
\hline \multirow{2}{*}{$\begin{array}{l}\text { Jesús } \\
\text { Martínez } \\
\text { Rojas }\end{array}$} & $\begin{array}{c}\text { Delegación chiapaneca } \\
\text { que se adhiere a la } \\
\text { candidatura de Francisco } \\
\text { I. Madero }\end{array}$ & 1911 & Colaborador & $\begin{array}{l}\text { 1. El hijo del pueblo, } \\
\text { 2. La voz de Chiapas, } \\
\text { 3. Más allá, } 4 \text {. La } \\
\text { libertad del sufragio }\end{array}$ & $\begin{array}{l}\text { 1. } 1911-1912, \\
\text { 2. } 1911.1912, \\
\text { 3. } 1910,4 . \\
1911-1912\end{array}$ \\
\hline & $\begin{array}{c}\text { Diputado Federal por } \\
\text { Chiapas }\end{array}$ & 1911 & Colaborador & $\begin{array}{l}\text { 1. El tribuno, 2. El bo- } \\
\text { letín del centenario }\end{array}$ & 1. 1917,1921 \\
\hline $\begin{array}{c}\text { Rafael } \\
\text { Pimentel } \\
\end{array}$ & Gobernador de Chiapas & $\begin{array}{l}1899- \\
1905 \\
\end{array}$ & & & \\
\hline \multirow{3}{*}{$\begin{array}{l}\text { Emilio } \\
\text { Rabasa }\end{array}$} & $\begin{array}{l}\text { Magistrado Presidente del } \\
\text { Tribunal Superior de } \\
\text { Justicia del Distrito Federal }\end{array}$ & 1888 & Colaborador & $\begin{array}{l}\text { La revista } \\
\text { chiapaneca }\end{array}$ & 1908 \\
\hline & Gobernador de Chiapas & $\begin{array}{l}1891- \\
1894\end{array}$ & Colaborador & Excélsior, El universal & \\
\hline & Senador & $\begin{array}{c}1894- \\
1898- \\
1910\end{array}$ & & & \\
\hline $\begin{array}{l}\text { Ramón } \\
\text { Rabasa }\end{array}$ & Gobernador de Chiapas & $\begin{array}{l}1905- \\
1911\end{array}$ & & & \\
\hline \multirow{2}{*}{$\begin{array}{l}\text { Querido } \\
\text { Moheno }\end{array}$} & Gobernador interino & 1911 & Colaborador & $\begin{array}{l}\text { 1. El demócrata, 2. El } \\
\text { porvenir de la Chon- } \\
\text { talpa, 3. Nuevo día }\end{array}$ & $\begin{array}{c}\text { 1. 1880, 2. ¿? } \\
\text { 3. ¿? }\end{array}$ \\
\hline & $\begin{array}{c}\text { Secretario de } \\
\text { Relaciones Exteriores }\end{array}$ & 1913 & Director & Nueva era & 1911 \\
\hline
\end{tabular}




\begin{tabular}{|c|c|c|c|c|c|}
\hline \multirow{4}{*}{$\begin{array}{l}\text { Reinaldo } \\
\text { Gordillo de } \\
\text { León }\end{array}$} & Gobernador interino & 1911 & & & \\
\hline & Gobernador de Chiapas & $\begin{array}{l}1911- \\
1912\end{array}$ & & & \\
\hline & $\begin{array}{l}\text { Presidente municipal de } \\
\text { Comitán }\end{array}$ & ¿? & & & \\
\hline & $\begin{array}{c}\text { Embajador en } \\
\text { Guatemala }\end{array}$ & 1913 & & & \\
\hline $\begin{array}{l}\text { Flavio A. } \\
\text { Guillén }\end{array}$ & Gobernador interino & $\begin{array}{l}1912- \\
1913\end{array}$ & Colaborador & El imparcial & $1877-1878$ \\
\hline \multirow{4}{*}{$\begin{array}{l}\text { Daniel A. } \\
\text { Zepeda }\end{array}$} & $\begin{array}{c}\text { Presidente del Congreso } \\
\text { del Estado }\end{array}$ & 1901 & & & \\
\hline & $\begin{array}{l}\text { Secretario general de } \\
\text { gobierno }\end{array}$ & 1902 & & & \\
\hline & Diputado suplente local & $\begin{array}{c}1896- \\
1898\end{array}$ & & & \\
\hline & $\begin{array}{c}\text { Diputado constituyente de } \\
\text { Querétaro }\end{array}$ & 1917 & & & \\
\hline \multirow{3}{*}{$\begin{array}{c}\text { José Antonio } \\
\text { Rivera } \\
\text { Gordillo }\end{array}$} & $\begin{array}{l}\text { Diputado federal suplente } \\
\text { por Chiapas }\end{array}$ & $\begin{array}{l}1900- \\
1902\end{array}$ & Colaborador & $\begin{array}{l}\text { 1. El demócrata, 2. El } \\
\text { diario del hogar }\end{array}$ & $\begin{array}{l}\text { 1. } 1880,2 . \\
\text { Siglo XIX }\end{array}$ \\
\hline & $\begin{array}{c}\text { Secretario de Gobierno } \\
\text { del DF }\end{array}$ & $\begin{array}{l}\text { 1911- } \\
\text { ¿? }\end{array}$ & Director & $\begin{array}{l}\text { 1. Chiapas y México, } \\
\text { 2. La clase media }\end{array}$ & $\begin{array}{c}\text { 1. 1908-1911, } \\
\text { 2. ¿? }\end{array}$ \\
\hline & $\begin{array}{l}\text { Presidente de la Colonia } \\
\text { Chiapaneca en el DF }\end{array}$ & 1908 & Director & $\begin{array}{l}\text { El mensajero } \\
\text { chiapaneco }\end{array}$ & 1911 \\
\hline \multirow{3}{*}{$\begin{array}{l}\text { Rubén } \\
\text { Valenti }\end{array}$} & $\begin{array}{l}\text { Subsecretario de Instrucción } \\
\text { Pública y Bellas Artes }\end{array}$ & 1912 & Colaborador & El heraldo de Chiapas & 1908 \\
\hline & Ministro de Justicia & 1914 & Colaborador & Savia moderna & 1906 \\
\hline & & & Redactor & El debate & ¿? \\
\hline
\end{tabular}

Fuente: Elaborada a partir de la consulta de los periódicos citados, informes de gobierno de la época (1901-1911) del Archivo Histórico de Chiapas y del libro de Enrique Pérez Mota ya citado.

Las tablas 2 y 3 exhiben las relaciones establecidas entre periodistas, intelectuales y políticos, así como el uso que estos últimos hacían de la prensa para demostrar influencia en una sociedad que en esos años era sobradamente analfabeta.

A principios del siglo XX, la prensa local documenta la disputa entre tuxtlecos y sancristobalenses por la sede de los poderes políticos. El conflicto involucró también a periodistas y políticos de Comitán, como cuando se convocó, en 1911, a la elección de un nuevo gobernador tras la caída del régimen porfirista y de Ramón Rabasa. Los tuxtlecos apoyaron la postulación del comiteco Reinaldo Gordillo de León. Los de San Cristóbal apoyaron a otro importante hombre de Comitán, José Antonio Rivera Gordillo. Otros personajes detectados en esta trama de relaciones son los siguientes:

- $\quad$ Emilio Rabasa

- Francisco Orozco y Jiménez (obispo de San Cristóbal de Las Casas)

- Manuel Rovelo Argüello 
- $\quad$ Policarpo Rueda

- Juan Espinosa Torres

- Jacinto Pérez "Pajarito" (de San Juan Chamula)

- Víctor Manuel Castillo

- Flavio Guillén

Las fricciones intentan ser resueltas en el centro del país, práctica heredada por los grupos políticos del régimen de Díaz a la nueva administración pública. Como se dijo antes, los políticos chiapanecos acudían a la Ciudad de México para fortalecer sus posiciones y sus redes con los grupos de poder a nivel federal. La colonia chiapaneca era un mecanismo institucional utilizado con este fin. Valente Molina (2014, p. 29) deja entrever cómo la figura de Emilio Rabasa se convierte en referente obligado durante el régimen de Porfirio Díaz, confrontado en su momento por José Antonio Rivera Gordillo, también empleado en la administración porfirista y radicado en la Ciudad de México, pero ideológicamente contrario al liberalismo de Rabasa y del General:

Ese año Rivera sacó a la luz la revista Chiapas y México, en cuyo primer número hizo votos para que la colonia "siga siendo unida". También anunció que en su revista hablaría "sin rodeos ni vacilaciones", y así lo hizo, con constantes críticas a los hermanos Rabasa y otros políticos, lo que generó que varios de sus colaboradores se abstuvieran de escribir por temor a represalias. ${ }^{5}$

La confrontación evidenciada en la prensa impacta asimismo en la creación literaria. Los diarios locales dejaban constancia del respaldo o rechazo a los políticos. Al figurar estas simpatías y repudios también en textos literarios, se entiende que los autores de éstos tampoco dejaban de tomar partido.

\section{LOS TEXTOS POÉTICOS EN LA PRENSA LOCAL (1901-1912)}

Durante la Colonia, los habitantes de Chiapas vivieron privados de los beneficios del centro guatemalteco de poder, además de ser mudos obser-

4 En el libro La colonia chiapaneca en el Distrito Federal. 1888-1950 narra su constitución llevada a cabo por el chiapacorceño Ángel Pola, de quien rescata los nombres de los primeros integrantes y amigos que se reunieron para conformarla, entre ellos Emilio Rabasa y José Antonio Rivera Gordillo.

5 Información ubicada en la página 77 del libro citado, donde Molina ahonda sobre dos hechos importantes: 1. La asunción de José Antonio Rivera Gordillo a la presidencia de la agrupación y 2. La primera elección efectuada en el seno de este grupo. El resultado favorece a quien se convierte en el rival político de Rabasa. 
vadores de la riqueza de sus vecinos novohispanos. Su situación no varió en el siglo XIX, cuando las élites decidieron incorporar el territorio a la naciente nación mexicana. A la entrada del siglo XX, cuando las condiciones sociales en el país cambiaron debido al intervencionismo de corte liberal del gobierno porfirista, centralista y autoritario, la mayor parte de la población chiapaneca era hablante de una lengua originaria y un porcentaje muy bajo, casi inexistente, sabía leer y escribir.

Avanzado el siglo XX, la aparición de escritores de la talla de Rosario Castellanos, Jaime Sabines y Eraclio Zepeda, no ha sido explicada tomando en cuenta las condiciones de pobreza y ausencia de educación imperantes en el estado. Como una explicación parcial de este fenómeno, es necesario considerar que la prensa, a finales del siglo XIX, estaba interesada en demostrar la existencia de una clase social educada para escribir poesía, ensayo, entre otros géneros literarios, y que hacía gala de un conocimiento de historia local e internacional, características que ayudan a entender el surgimiento de un grupo interesado en la creación literaria.

Presionadas por una política nacional centralista, la prensa y las élites chiapanecas modificaron su discurso para demostrar fuerza y poder influir en las decisiones del gobierno. Los ejemplos retomados para ilustrar cómo el cambio social generado por los sucesos políticos en el país afectó la creación literaria de esos años comprenden el periodo de 1901 a 1912.

A continuación se citan algunos versos que muestran cómo la poesía mudó de un romanticismo tardío en 1901 a un tono irónico y con fuerte carga de crítica política y social en 1911 para después, en 1913, volver a tratar temas emocionales o paisajísticos.

El primer ejemplo lo ofrece el periódico de Comitán El clavel rojo, del 16 de septiembre de 1901, página 3, ahí se lee un poema de tintes épicos, en verso rimado, de dos cuartetas y una quinteta:

\section{Púrpura $^{6}$}

Para José Antonio Rivera G.7

Enrique Torres Torija

En la arena del circo, rebosante

de loca multitud que vocifera,

6 En ésta como en el resto de las composiciones citadas son respetadas fielmente la tipografía (itálicas o negritas en el título) y faltas de ortografía originales.

7 José Antonio Rivera Gordillo es un personaje central en el conflicto entre el grupo de San Cristóbal de Las Casas, de corte católico, y el grupo tuxtleco, de alineación rabasista. La disputa más visible es la traslación de los poderes, pero se aprecia escasamente el interés por la conformación de una política y un estado católicos. 
el gladiador, cansado y anhelante, sucumbe entre las garras de la fiera.

Es grandiosa y solemne su agonía, como estética y grave su postura; sus músculos resultan con la fría desnudez de una trágica escultura.

Y en tanto que la plebe palmotea al Hercules [sic] muriente y taciturno que fue vencido en desigual pelea, la mirada del tigre centellea como un ojo de cíclope nocturno.

La publicación de poemas dedicados a personajes de relevancia política y amigos es frecuente en la prensa de la época; aparecen al mismo tiempo otros versos más sentimentales, amorosos, como los del siguiente soneto, con un dejo musical en la rima y de influencias becquerianas por el encanto de sus imágenes. Su autor es Ranulfo Penagos y fue publicado en el periódico El heraldo de Chiapas en su edición del 4 de junio de 1908, página 3:
Amor
Deja que oprima con presión vehemente
tu airoso talle de palmera erguida, y que mire en tus ojos encendida
la hoguera del amor más elocuente.
Deja que bese con mi labio ardiente tu dulce boca, que a besar convida, y que luego te vea conmovida sintiendo el goce que mi pecho siente.
Yo quisiera, mi bien, entre tus brazos, hayar [sic] la gloria de soñar cautivo de tu acento el orgullo plañidero...
Ven! [sic] Que ya unidos con eternos lazos sere [sic] inmortal, si para amarte vivo, seré feliz, si por quererte muero! [sic]

La aparición de la naturaleza es perceptible en el siguiente poema de corte sentimental, un poco desfasado para su época, como dice Armando Duvalier 
(1969, p. 20) y que es, según Jesús Morales Bermúdez (1997, p. 59), “Una poesía que se resuelve en metros y estrofas sencillas, en imágenes escasas y más bien descriptivas que sugerentes o audaces”. Su autor, José Emilio Grajales, pariente de quien fuera gobernador de Chiapas de 1948 a 1952, también es recordado entre sus paisanos por ser el autor de la letra del himno chiapaneco. Los versos fueron publicados en el periódico El heraldo de Chiapas el 23 de septiembre de 1909, en la página 3:

\section{En la montaña}

J. Emilio Grajales

Al caer la tarde

Las estrellas aparecen

Con sus fulgores de plata

En un cielo que embellecen

Nubecillas de escarlata.

En las hojas gime el viento,

Canta en su sonido el sinsonte

Ya soñado, y es su acento

Como un suspiro del monte.

Un carpintero en un roble

Haciendo de fuerza alarde,

Con un bélico redoble

Se despide de la tarde.

En pintoresca bandada,

Las guacamayas vistosas

Van cruzando la hondonada

De las lomas y zacatosas.

En la rama de un castaño

Corpulento y deshojado,

Con aire torvo y huraño

Un gavilán se ha parado,

De un amate en la alta copa

Somnolienta y agrupada.

Ya la noche se avecina,

8 En la presentación del libro Flores silvestres, de José Emilio Grajales, Armando Duvalier lo dice de la siguiente manera: "A pesar de que vivió cuando estaba en su apogeo la escuela modernista, solo [sic] algunas composiciones, como Cita y Las Ondinas, se deben catalogar dentro de ella, pues fue un romántico en toda la extensión de la palabra..." 
Está obscuro el horizonte,

Una errante golondrina

Vuela rauda sobre el monte,

De la luna los fulgores

En todo ponen congojas.

Parecen negras las flores

Y negras también las hojas,

Del bosque en la oscuridad.

Que oculta peñas y abrojos,

Con siniestra claridad.

Se ven brillar muchos ojos,

Otro mundo es la montaña.

Se ven allí cosas graves,

Un tigre raja una entraña

Y se despluman las aves.

Ante los acontecimientos sociales de México, en Chiapas los cambios políticos se perciben de inmediato. Aparecen poemas como el siguiente de Límbano Domínguez, de estructura sencilla, de tres estrofas en versos rimados bajo la estructura de cuartetos y publicado también en El Eco, el 6 de junio de 1910, en la página 2:

\section{Los tiranos}

Límbano Domínguez

Rara miseria que en la ley se escuda

Y perversa a los pueblos sacrifica:

Rara miseria cuya faz sañuda

Con la sangre inocente se salpica.

Pronto sucumbirá, pues ya el oleaje

De la emancipación rugiente avanza.

Cual fuego vengador que á tanto ultraje

A guerra sin cuartel presto se lanza.

Podeis [sic] temblar, que ufanos ya cantamos

El triunfo del derecho redentor

A cuya causa todos consagramos

Ardiente patriotismo y mucho amor.

Composiciones como la anterior son escasas porque los acontecimientos nacionales llegan tardíamente a oídos de la población local. Los escritores 
continúan haciendo del verso un ejercicio de entretenimiento, lúdico en su intención, como se observa en el siguiente ejemplo, publicado en el mismo periódico el 19 de junio de 1910, en la página 3:

\section{Un consejo}

Chema

Si quieres, buen amigo, hacer un trato,

O pensares, por ventura hacer el oso,

Anda luego a la casa de Barroso,

A sacar de tu persona, un buen retrato.

Y después, al pasar por la hostería,

Del buen Paco, sin decirle cacarizo,

Es preciso que le pidas un buen guiso,

Sin pensar, que beber, es tontería,

No te extrañe, si en la calle, o en su puerta,

O sentado, devanándose los sesos,

Encontrares algún "Chema" haciendo versos,

Es mi viejo, buen amigo, Lucas Huerta.

Con la caída del General Díaz y la ascensión de Madero, los impresos cotidianos se convierten en los voceros del conflicto entre la élite de San Cristóbal de Las Casas y la de Tuxtla Gutiérrez, motivado en apariencia por la traslación de poderes. Debido al temor que suscitan, los asuntos nacionales son tocados elípticamente, cuando no ignorados. En tanto, el tema local es el principal.

Los impresos más importantes toman partido, como se aprecia a continuación. Desde San Cristóbal de Las Casas, Neftalí R. Soto - aliado de la causa sancristobalense, contraria al grupo político rabasista tuxtleco-dirige El gavilán del 7 de noviembre de 1911. En los versos siguientes, publicados en la página 4, se alude a Reinaldo Gordillo de León, quien fuera identificado como el candidato rabasista al gobierno del estado ese mismo año.

Hay gordos que son gordillos,

Y leones que no son leones;

Pero también hay caudillos

Tan bajos como tacones.

En la bella Comitán

Hay Gordillos y hay Domínguez

Para fregar?... [sic] con loco afán

Grita el pueblo no la... ensucies. 
En Tuxtla Gutiérrez, el bando aludido responde haciendo gala de humor en el periódico Chamula G, del 15 de diciembre de 1911, página 1. El poema utiliza la figura del "león" para identificar a Reinaldo Gordillo de León como un personaje superior al grupo contrario, representado por el "chamulita" de los versos. Recuérdese que el intento de la invasión indígena a Tuxtla Gutiérrez, en esa época, fue encabezada por un chamula.

Este era un chamulita

Que á las montañas salió

A cazar gubernatura

Con su perro bulldog,

Y como se encontrara con un león,

Trepóse a un guayabo

Do la vida escapó,

Más como el león le esperara,

En la punta se quedó,

$\mathrm{Y}$ el infeliz perrito

Cuando solo se vio

Al frente del leoncito

Tan bravo y tan feroz,

Retrocedió quedito,

Ocultándose, ¡Oh dolor!

En el tronco del guayabo

Do león ya no lo vió

Quien como meneara el rabo

Aquel allá se quedó.

¿Dónde, manito?

¡Pos no pusiste cuidado al cuento!

Como se observa, la construcción poética cambia en forma y contenido; los noticiosos muestran abundantes ejemplos, algunos más logrados que otros. Para este trabajo, estos poemas y los siguientes dan fuerza al argumento manejado hasta ahora: los acontecimientos políticos inciden en la creación literaria.

Antes de presentar más evidencias sobre el tema central, se reproduce un epigrama que insiste en la participación de Emilio Rabasa en la era postporfiriana. Firmado por "Periquillo", este cuarteto de versos humorístico muestra claramente su antipatía ante lo que se consideraba "rabasista" y es publicado en El gavilán del 2 de enero de 1912, página 2:

En Tuxtla sembré, otro día,

Una enorme calabaza; 
Y otra vez salió una guía

De la dinastía Rabasa.

El 3 de diciembre de 1911, el periódico tuxtleco 30-30, en su página 2, expone al Obispo de San Cristóbal, don Francisco Orozco y Jiménez, al vincularlo a los sucesos y al conflicto entre los dos bandos, tal como se lee en este poema:

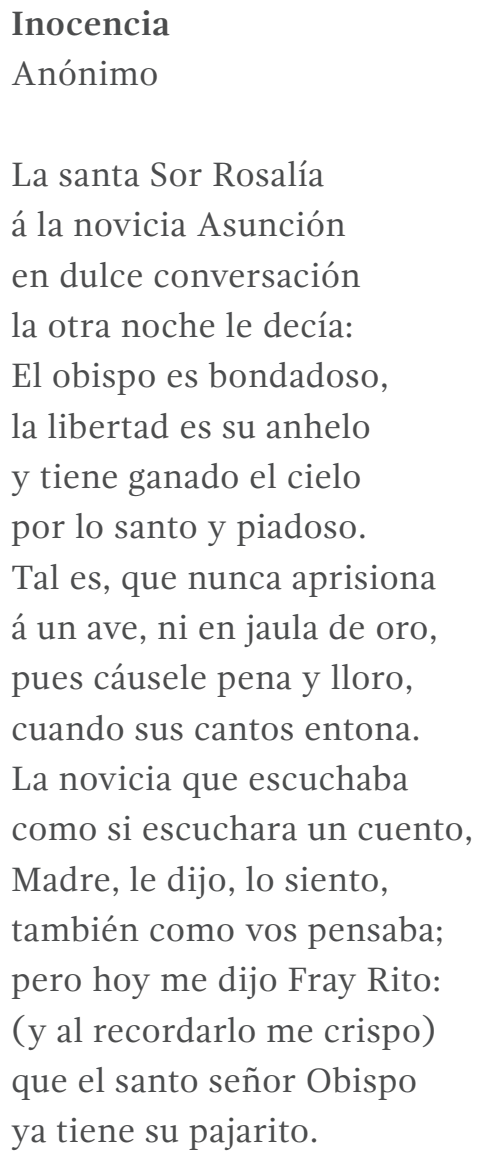

Los hechos noticiosos sucedieron en 1910, 1911 y 1912; todos relacionados con la caída de Díaz, luego de Madero y en el corto tiempo de Huerta al frente del poder ejecutivo nacional. Los grupos locales aprovecharon esta situación para tomar el control político o conservarlo. Los bandos utilizaron distintos argumentos; algunas veces, los escritores añoraron un pasado menos agitado, como en el epigrama firmado por Fray Candil y publicado en el periódico 30-30, del 7 de enero de 1912, página 2, que continúa la controversia entre tuxtlecos rabasistas y religiosos sancristobalenses: 
Más [sic] ¡hay! Aquellos [sic] tiempos de tan feliz memoria Cual ondas se empujan, pasaron y no son.

Mis ojos vierten lágrimas al recordar la historia

Y ver cuán prostituida está la religión...

En 1912 continúa la pugna entre los dos bandos. Al mismo tiempo, los autores dejaban ver su formación académica y su conocimiento de las técnicas discursivas y poéticas, pues abordaban distintos géneros y estilos. Así lo demuestra el uso de la argumentación, la amplitud del vocabulario, los localismos y, por supuesto, el humor. En el siguiente poema pueden observarse estas características. Firmado por "Gustavo", fue publicado en el periódico Francisco Cuscate del 11 de abril de 1912, página 4:

"AL GAVILAN"9 [sic]

Mi cabeza parece un horno

Cuando me pongo a pensar

Lo fácil que es provocar

Un gramatical trastorno.

Porque yo hablo sin adorno

Y á la opinión le doy vuelo;

"Gavilán" me cree repelo,

Deje que me lea el que guste,

$Y$ al que no lo guste el fuste

Y mi parodia un cuadre,

Que tire parodia y fuste

$\mathrm{Y}$ vaya y monte en su... abuelo.

Con la llegada del General Bernardo Z. Palafox como gobernador del estado, los grupos locales de poder son sometidos y los periódicos limitan su participación política a su función de instrumentos de comunicación del gobierno en turno. En los textos poéticos la abierta beligerancia política desaparece también.

\section{REFLEXIONES FINALES}

La lucha por el poder político en Chiapas, así como la disputa entre San Cristóbal de Las Casas y Tuxtla Gutiérrez por la residencia oficial de los

9 El gavilán fue un periódico publicado en San Cristóbal de Las Casas, dirigido por Neftalí R. Soto (tabla 2), periodista y poeta de corte romántico. 
poderes estatales, generó un discurso periodístico que representaba a las élites en pugna y evidenciaba las relaciones entre los intelectuales y las autoridades que detentaban el poder, práctica heredada por décadas previas y continuada en posteriores. ${ }^{10}$

Este dato parece contradictorio si se compara con las estadísticas de educación en el estado, sin embargo, el hecho se explica por la promoción de élites sociales cuya instrucción fue fundamental para recuperar espacios de poder perdidos, como sucedió en San Cristóbal de Las Casas. Debe recordarse que la antigua Ciudad Real fue capital de la provincia de Chiapas, adscrita a la Capitanía General de Guatemala, estatus que perdió por varias razones y posteriormente intentó recobrar. Para su infortunio, las condiciones sociopolíticas desarrolladas durante el siglo XIX hicieron que nuevos grupos de poder consolidaran un contexto político diferente a través de los nexos establecidos con el poder central del país. Así lo demuestra, por ejemplo, el epigrama de El gavilán, del 2 de enero de 1912, arriba citado. Ahí se señala como enemigo a Emilio Rabasa, un político encumbrado durante el régimen de Porfirio Díaz y que supo mantener sus relaciones en las administraciones siguientes.

Los versos comentados ofrecen un testimonio sobre las relaciones políticas, intelectuales y sociales aún por estudiarse con mayor detalle. Ofrecen formas de representación de hechos históricos como las pugnas políticas de la época, imágenes facturadas por élites que pretendían construir, mantener o destruir perfiles políticos. También demuestran cómo la vida social y política motivaron el uso de la función poética del lenguaje entre los periodistas e intelectuales de la época, impulsando el desarrollo artístico de la escritura. Una línea de creación que, años más tarde, generó personalidades que trascendieron las fronteras locales como Rosario Castellanos o Jaime Sabines. En ambos casos, el contexto y las prácticas brindaron oportunidades para el desarrollo de las habilidades creativas a través de la prensa.

10 Léanse mis artículos: 2015 “La ficción y la poesía en la revista Chiapas" en Márquez Espinosa, Esaú y María del Rocío Ortiz Herrera (Eds.) Sociedades encauzadas: geografía, historia y realidad. Tuxtla Gutiérrez: Universidad de Ciencias y Artes de Chiapas; y 2013 “Chiapas. La construcción de una élite cultural a través de la prensa" en Anuario 2012. Tuxtla Gutiérrez: Universidad de Ciencias y Artes de Chiapas. 


\section{REFERENCIAS}

Grajales, José Emilio. (1969). Flores silvestres. Tuxtla Gutiérrez: (sin editorial). Márquez Espinosa, Esaú y Ortiz Herrera, María del Rocío (Eds.). (2015). Sociedades encauzadas: geografía, historia y realidad. Tuxtla Gutiérrez: Universidad de Ciencias y Artes de Chiapas.

Martínez, Sarelly. (2004). La prensa maniatada. El periodismo en Chiapas de 1827 a 1958. México: Fundación Manuel Buendía.

Molina, Valente. (2014). La colonia chiapaneca en el Distrito Federal. 1888-1950. Tuxtla Gutiérrez: Consejo nacional para la Cultura y las Artes, Consejo Estatal para las Culturas y las Artes y Universidad Autónoma de Chiapas.

Morales Bermúdez, Jesús. (1997). Aproximaciones a la poesía y la narrativa de Chiapas. Tuxtla Gutiérrez: Universidad de Ciencias y Artes de Chiapas.

Pérez Mota, Luis Enrique. (1994). Chiapas: Notas para una historia reciente. Tuxtla Gutiérrez: Congreso del estado de Chiapas, Universidad Autónoma de Chiapas e Instituto Chiapaneco de Cultura.

Serrano Aranda, Raúl. (2010). Crónica de los gobernadores de Chiapas en el Bicentenario 1825-1910. Sus obras, sus perfiles y sus epigramas. Tuxtla Gutiérrez: Gobierno del Estado de Chiapas. 